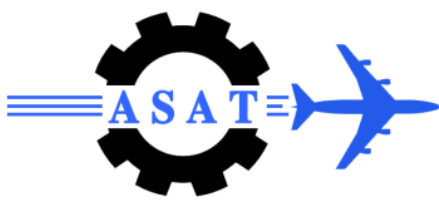

\title{
Dynamic Analysis of a Rotating Composite Shaft
}

\author{
S.M. Ghoneam ${ }^{*}$, A.A. Hamada ${ }^{\dagger}$ and M.I. EL-Elamy*
}

\begin{abstract}
This paper is concerned with the dynamic analysis of a rotating composite shaft. The numerical finite element technique is utilized to compute the eigen pairs of laminated composite shafts. A finite element model has been developed to formulate the stiffness matrices using lamination theory. These matrices take into account the effects of axial, flexural and rotating on the eigen-nature of rotating composite shaft. The Campbell diagram is utilized to compute the critical speed of rotating composite shaft and instability regions to achieve accuracy and for controlling the dynamic behavior of the system in resonance state.
\end{abstract}

The influence of laminate parameters: stacking sequences, fiber orientation, boundary conditions and fiber volume fractions effect on natural frequencies and instability thresholds of the shaft are studied. The results are compared to those obtained by using the finite element method and experimental measurements using frequency response function method (FRF) by applying the autogenously excitation "from self excitation due to driving motor". In the experimental part, the response of composite shaft with various types of boundary conditions and five lamina orientations were recorded and analyzed by utilizing fast Fourier transform dual channel analyzer in conjunction with the computer.

The comparison between the numerical and experimental results proves that the suggested finite element models of the composite shaft provide an efficient accurate tool for the dynamic analysis of rotating composite shaft.

Keywords: Rotating Composite Shaft, Finite Element, Damping, Dynamic analysis

\section{Introduction}

Composite materials have interesting properties such as high strength-to-weight ratio, compared to metals, which make them very attractive for rotating systems. Attempts are being made to replace metal shafts by composite ones in many applications: drive shafts for helicopters, centrifugal separators, and cylindrical tubes for the automotive and marine industries. They also provide designers with the possibility of obtaining predetermined behaviors, in terms of position of critical speeds, by changing the arrangement of the different composite layers: orientation and number of plies.

\footnotetext{
* Prof of Dynamics \& Tribology, Faculty of Engineering, Menoufiya University, Shebin El-Kom, Egypt, Ghoneam22000@ Yahoo.com.

$\dagger$ Assoc. Prof. Faculty of Engineering, Menoufiya University, Shebin El-Kom, Egypt, a_hamed_59@yahoo.com

$¥$ Assis. Lecturer, Faculty of Engineering, Menoufiya University, Shebin El-Kom, Egypt, mamdouhelimi@yahoo.com
} 
On the other hand, these materials have relatively high-damping characteristics. For a rotor made with composite materials, internal damping is much more significant companied with those associated with a metal rotor. O. Bauchau [1] described a boron/epoxy composite tail rotor drive shaft for a helicopter. The critical speeds were determined using equivalent modulus beam theory (EMBT), assuming the shaft to be a thin-walled circular tube simply supported at the ends. The shaft critical speed was determined by extrapolation of the unbalance response curve which was obtained in the subcritical region. E. Chatelet et al. [2] published analytical investigations on thin-walled layered composite cylindrical tubes. In part III of the series of publications, the beam element was extended to formulate the problem of a rotor supported on general eight coefficient bearings. Results were obtained for shaft configuration of Zinberg and Symmonds. The authors have shown that bending-stretching coupling and shear-normal coupling effects change with stacking sequence, and alter the frequency values. LW. Chen, and WK. Peng [3] studied the effect of shear-normal coupling on rotor natural frequencies and modal damping. MS. Darlow and J. Creonte [4] have formulated the problem of determination of critical speeds of a composite shaft including the effects of bending-twisting coupling. The shaft was modeled as a Bresse-Timoshenko beam. The shaft gyroscopics have also been included. The results compare well with Zinberg's rotor [1]. In another study, Y.S. Lee and Y.W. Kim [5] have analyzed the dynamic instability of a composite drive shaft subjected to fluctuating torque and/or rotational speed by using various thin shell theories. The rotational effects include centrifugal and Coriolis forces. Dynamic instability regions for a long span simply supported shaft are presented.

JC. Pereira et al. [6] published the vibration behaviors of the rotating composite shafts. In the model, the transverse shear deformation, rotary inertia, and gyroscopic effects, as well as the coupling effect due to the lamination of composite layers have been incorporated. The model is based on a first-order shear deformable beam theory (continuum based Timoshenko beam theory). A. AL. Kimball [7] presented the dynamic behavior of the rotating composite shaft on rigid bearings. A $p$-version, hierarchical finite element is employed to define the model. A theoretical study allows the establishment of the kinetic energy and the strain energy of the shaft, necessary for formulating of the equations of motion. In this model the transverse shear deformation, rotary inertia and gyroscopic effects, as well as the coupling effect due to the lamination of composite layers have been incorporated.

M. Lalanne et al. [8] presented the dynamic performance and cross-section deformation of shafts made of metals (steel and aluminum), composites (CFRP and GFRP) and hybrids of metals and composites have been studied. A layered finite degenerated shell element with transverse shear deformation and dynamic behavior is employed. Results obtained show that improvements in dynamic performance and reduction of cross-section deformation of hybrid shafts over metallic and composite shafts are possible.

A mathematical model, based on Timoshenko beam assumption, for a rotating cylindrical shaft with cylindrical constrained layer damping treatment is developed by Ghoneim and Lawrie [9]. The model is developed for a shaft made of composite materials, and treated with a cylindrical constrained layer damping partially covering the length span of the shaft. The discrete equations of motion are developed using two methods: the finite element method and the assumed mode method. The developed equations are applied to study the effect of some geometric and material parameters on the flexural stiffness and damping of the shaft, with emphasis on the coverage length of the cylindrical constrained layer treatment. 
The present work is concerned with the dynamic analysis of a rotating composite shaft. The numerical finite element technique is utilized to compute the eigen pairs of laminated composite shafts. A finite element model has been developed to formulate the stiffness matrices using lamination theory. These matrices take into account the effects of axial, flexural and rotation on the eigen-nature of rotating composite shaft. The Campbell diagram is utilized to compute the critical speed of rotating composite shaft and instability regions to achieve accuracy and for controlling the dynamic behavior of the system in resonance state.

The results are compared to those obtained by using the finite element method and experimental measurements using frequency response function method (FRF) by applying the autogenously excitation.

\section{Materials and Production of Laminates Composite Shaft}

Glass fiber is used as reinforcement in the form of bidirectional fabric (Standard E-Glass Fiberglass) and polyester with catalyst addition as matrix for the composite material. The mechanical properties of the composite are calculated analytically using the mixture rule [10].

Through hand lay-up process followed by a cure process, five sets of symmetrical laminates with a total of five layers each one are produced:

Set1: [0/0/0/0/0], Set2: [0/30/0/30/0], Set3: [0/45/0/45/0] Set4: [0/60/0/60/0] and Set5: $[0 / 90 / 0 / 90 / 0]$. The numbers mentioned in the above sets indicate the angle of fiber inclination measured in degrees.

After the cure process, the laminated composite shaft dimensions with length of $790 \mathrm{~mm}$ and $18 \mathrm{~mm}$ diameter and average mass specimen equal to $0.250 \mathrm{Kg}$.

A typical specimen made from fiber reinforced plastic FRP composite shafts formed from five plies with $1 \mathrm{~mm}$ thickness for each ply is shown in Fig. 1. Three composite levels were selected for each code number. These are specimens with low fiber volume fraction $\boldsymbol{V}_{\boldsymbol{f}}=\mathbf{2 5 \%}$ and two level of average fiber volume fraction $V_{f}=\mathbf{4 5} \%$ and $\mathbf{6 5 \%}$. The fiber volume fraction in the specimens is determined experimentally, using the firing processes method [11]

In order to study the effect of lamina orientation and staking sequence on the modal parameters, five code numbers of the specimens were fabricated and stated for each fiber volume fraction.

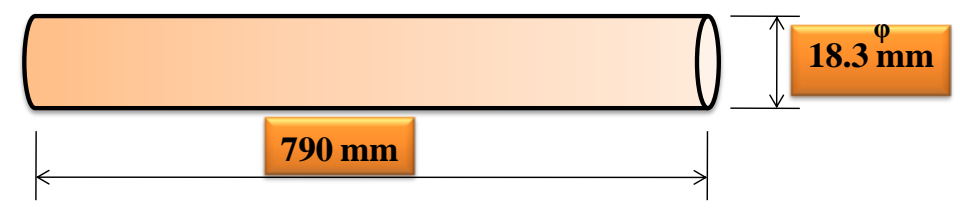

Fig. 1 Three-dimensional specimen of composite shaft. 


\section{Theoretical Investigation}

The present theoretical study is used to compute the mechanical properties of laminated composite shaft using mixture rule shown in Fig. 2. The laminate extensional, coupling and bending stiffness matrices of composite symmetric laminated composite shaft with different predetermined lamina orientations are computed on the basis of the classical lamination theory [12].

Table 1 Mechanical properties of the composite shaft using the mixture rule with $\left(V_{f}=25 \%, 45 \%\right.$ and $\left.60 \%\right)$.

\begin{tabular}{l|c|c|c}
\hline \multirow{2}{*}{ Elastic modulus } & \multicolumn{3}{|c}{ Results using Mixture rule } \\
\cline { 2 - 4 } & $\boldsymbol{V}_{\boldsymbol{f}}=25 \%$ & $\boldsymbol{V}_{\boldsymbol{f}}=45 \%$ & $\boldsymbol{V}_{\boldsymbol{f}}=65 \%$ \\
\hline $\boldsymbol{E}_{\boldsymbol{1 1}},[\mathrm{Gpa}]$ & 20.75 & 34.51 & 48.3 \\
$\boldsymbol{E}_{\boldsymbol{2 2}},[\mathrm{Gpa}]$ & 4.60 & 6.12 & 9.2 \\
$\boldsymbol{G}_{\boldsymbol{1 2}},[\mathrm{Gpa}]$ & 2.29 & 2.58 & 2.9 \\
$\boldsymbol{v}_{12}$ & 0.27 & 0.29 & 0.302 \\
$\boldsymbol{v}_{21}$ & 0.06 & 0.052 & 0.058 \\
\hline \hline
\end{tabular}

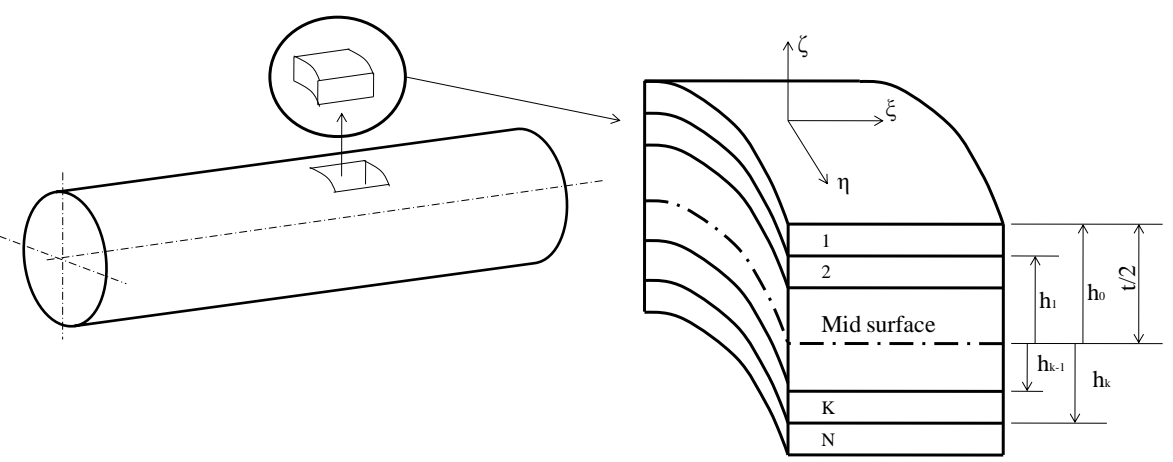

Fig. 2 Composite laminated shaft [13].

\subsection{Finite Element Formulation}

The cylindrical composite shaft shown in Fig. 2 is assumed to be built up by a number of lamina perfectly bonded together [13]. There are no relative displacements between adjacent layers [14].

The finite element used has eight nodes as shown in Fig. 3. For each node, the element has four degrees of freedom: two displacements $\mathrm{u}$ and $\mathrm{w}$, and two slopes about the $\mathrm{x}$ and $\mathrm{y}$ axes denoted, respectively $\theta$ and $\varphi$. In this case, the beam axis is z. Referring to Fig. 3, the displacement field at a point in the element can be expressed in global coordinates as

$$
\left[\begin{array}{ll}
u & w
\end{array}\right]^{T}=\sum_{k=1}^{6}\left[\overline{N^{k}}\right]\left\{d^{k}\right\}
$$

where $\left[N^{k}\right]$ the generalized shape function matrix and $\left\{d^{k}\right\}=[u w \theta \varphi]^{T}$ is the nodal displacement vector. The strain matrix $[\mathrm{B}]$ relating the strain components in the local system to the element nodal variables can be expressed as 


$$
\{\varepsilon\}=\sum_{K=1}^{9}\left[B^{k}\right]\left\{d^{k}\right\}
$$

As shown in Fig. 2, the natural coordinate $\zeta$ varies from -1 to +1 , is determined at the middle point of each layer and strain-stress components and stiffness contributions are computed at the midsection of each layer. Consequently, the volume integral may be split into integrals over the area of the shell midsurface and through the thickness t. Thus the stiffness can be written as

$$
\left[K_{e}\right]=\int_{-1}^{1} \int_{-1}^{1} \int_{-1}^{1}[B]^{T}[\bar{D}][B]|J| d \zeta d \xi d \eta
$$

where $|J|$ is the determinant of the Jacobian matrix for layer $\mathrm{j}$. The matrix $[\bar{D}]$ is the material transformed stiffness matrix which can be expressed as $[\bar{D}]=[T]^{-1}[D][T]$. Here $[\mathrm{T}]$ and $[\mathrm{D}]$ are the transformation and material stiffness with respect to the local coordinates matrices respectively. Different elements of the [D] matrix can be written as

$$
[D]=\left[\begin{array}{ccccc}
D_{1} & D_{12} & 0 & 0 & 0 \\
D_{12} & D_{2} & 0 & 0 & 0 \\
0 & 0 & G_{12} & 0 & 0 \\
0 & 0 & 0 & K G_{12} & 0 \\
0 & 0 & 0 & 0 & K G_{12}
\end{array}\right]
$$

where $D_{1}=E_{1} / \Delta, D_{2}=E_{2} / \Delta, D_{12}=E_{2} v_{12} / \Delta, \Delta=1-v_{12} v_{21} . \mathrm{K}$ is shear correction factor.

The element consistent mass matrix at layer $\mathrm{j}$ linking nodes $\mathrm{i}$ and $\mathrm{j}$ can be written as

$$
\left[M_{e}\right]=\int_{-1}^{1} \int_{-1}^{1} \int_{-1}^{1}\left[N_{i}\right] \rho_{c}\left[N_{j}\right] d \zeta d \xi d \eta
$$

where, $\rho_{c}$ is the density of composite shaft; $[\mathrm{Ni}],[\mathrm{Nj}]$ are the matrices of shape function.

The free vibration of an undamped system results into an eigen-value problem. The generalized eigen-value problem can be expressed as

$$
\left[[K]-\omega^{2}[M]\right]\{X\}=0
$$

where $[\mathrm{K}],[\mathrm{M}]$ and $\{\mathrm{X}\}$ are the global stiffness, mass and displacement matrices which are generated through the assembly of elements local matrices; $\omega$ is the undamped natural frequency.

In view of Eq. 5, the program has been coded into computer using Matlab (7.1) [15]. The program computes the eigen-values and eigenvectors for five code numbers and for four boundary fixations namely C-C, C-S, S-S and C-F. The results of FEM are listed in Table 2. 


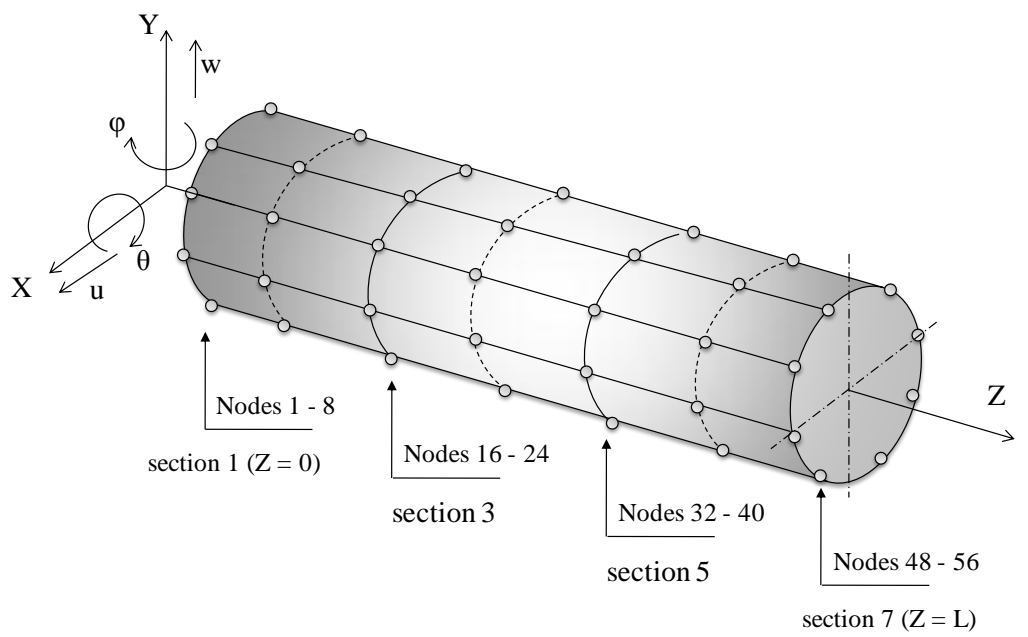

Fig. 3 Finite elements of composite shaft.

Table 2 Values of fundamental frequency in $\mathrm{Hz}$ for various laminated orientations and different boundary fixation (Finite Element Method)

\begin{tabular}{|c|c|c|c|c|c|}
\hline \multirow{2}{*}{\multicolumn{2}{|c|}{$\begin{array}{l}\text { Lamina orientation and } \\
\text { boundary fixations }\end{array}$}} & C-C & C-S & S-S & C-F \\
\hline & & $\mathrm{FE}$ & $\overline{F E}$ & $\overline{F E}$ & $\mathrm{FE}$ \\
\hline$[0 / 0 / 0 / 0 / 0]$ & \multirow{5}{*}{$\begin{array}{l}0^{0} \\
2 \\
11 \\
n^{+}\end{array}$} & 268.3 & 176.2 & 115.2 & 43.1 \\
\hline$[0 / 30 / 0 / 30 / 0]$ & & 224.6 & 147.1 & 96.1 & 37.2 \\
\hline$[0 / 45 / 0 / 45 / 0]$ & & 179.1 & 115.1 & 75.7 & 29.6 \\
\hline$[0 / 60 / 0 / 60 / 0]$ & & 156.2 & 104.1 & 66.9 & 26.1 \\
\hline$[0 / 90 / 0 / 90 / 0]$ & & 124.5 & 83.5 & 54.1 & 21.4 \\
\hline$[0 / 0 / 0 / 0 / 0]$ & \multirow{5}{*}{$\begin{array}{l}0^{0} \\
i n \\
y^{\prime} \\
>^{4}\end{array}$} & 325.2 & 215.4 & 135.1 & 50.4 \\
\hline$[0 / 30 / 0 / 30 / 0]$ & & 273.4 & 178.1 & 116.4 & 44.5 \\
\hline$[0 / 45 / 0 / 45 / 0]$ & & 218.1 & 139.8 & 91.5 & 36.0 \\
\hline$[0 / 60 / 0 / 60 / 0]$ & & 187.3 & 121.3 & 79.6 & 29.7 \\
\hline$[0 / 90 / 0 / 90 / 0]$ & & 151.3 & 97.0 & 65.3 & 24.1 \\
\hline$[0 / 0 / 0 / 0 / 0]$ & \multirow{5}{*}{$\begin{array}{l}00 \\
i n \\
\|^{2} \\
>^{4}\end{array}$} & 399.4 & 261.3 & 168.6 & 61.5 \\
\hline$[0 / 30 / 0 / 30 / 0]$ & & 332.1 & 219.8 & 140.6 & 50.7 \\
\hline$[0 / 45 / 0 / 45 / 0]$ & & 261.2 & 169.7 & 112.8 & 39.9 \\
\hline$[0 / 60 / 0 / 60 / 0]$ & & 229.7 & 148.5 & 96.7 & 36.2 \\
\hline$[0 / 90 / 0 / 90 / 0]$ & & 178.3 & 117.4 & 75.6 & 28.9 \\
\hline
\end{tabular}

\subsection{Fundamental Frequency of Transverse Vibration}

Dunkerley deduced that the whirling speeds were equal to the natural frequencies of transverse vibration, there being the same number of whirling speeds as natural frequencies for a given system. Thus a theoretical value for the critical speed may be obtained from the formula for the fundamental frequency of transverse vibrations:

$$
f_{s}=\left[\frac{E_{c} I_{s} g}{W_{S} L^{4}}\right]^{0.5} C
$$

where:

$E_{c}=$ computed elastic modules of composite shaft (MPa)

$f_{s}=$ natural frequency of transverse vibrations $(\mathrm{Hz})$ 
$I_{s}=$ second moment of area of shaft

$W_{s}=$ weight per unit length of shaft

$\mathrm{g}=$ acceleration due to gravity

$\mathrm{C}=$ constant dependent upon the boundary conditions

The elastic modules of composite shaft of five layers ware calculated using lamination theory according to lamina orientation and layer thickness [16]. The value $\mathrm{C} 1$ is the constant for use in calculating the first natural frequency and $\mathrm{C} 2$ is that necessary for the second mode [17].

\section{Experimental Investigation}

In the present experimental part the measurements of laminated composite shaft for various five lamina orientations, three different fiber volume fraction ratio and four boundary fixations are constructed and manufactured using winding layup method. The boundary conditions of a rotating composite shaft were achieved using a combination of various bush width and a rate level of bearing clearance two obtain a proper boundary fixation state.

The dynamic analysis in the experimental results in qualitative and quantitative manner is presented to investigate their dynamic eigen-parameters including natural frequencies, damping factors and critical speed.

\subsection{Composite Shaft Specimen Preparations}

Figure 4 shows the rotating composite shaft manufacture at various types of lamina orientations angles. The preparation and manufacturing of specimens are achieved by following the standard procedures [18]. Five layers of $(\mathbf{1 m m})$ thickness were wound by the required angle and spread on a wood Die at various orientation fibers. A layer of resin is spread on a wood Die treated by release agent (Wax or medical Vaseline). The wood Die $(1000$ long $\times 18.3 \mathrm{~mm}$ diameters $)$ is then placed on the glass fiber and assembled together by copper wire, closing gap by cement. The press die was removed after $\mathbf{2 4}$ hours and the laminate has been completely cured at room temperature. The laminate composite shafts are cut to the required length $(790 \mathrm{~mm}$ long $)$ using mechanical fine sawing machines.

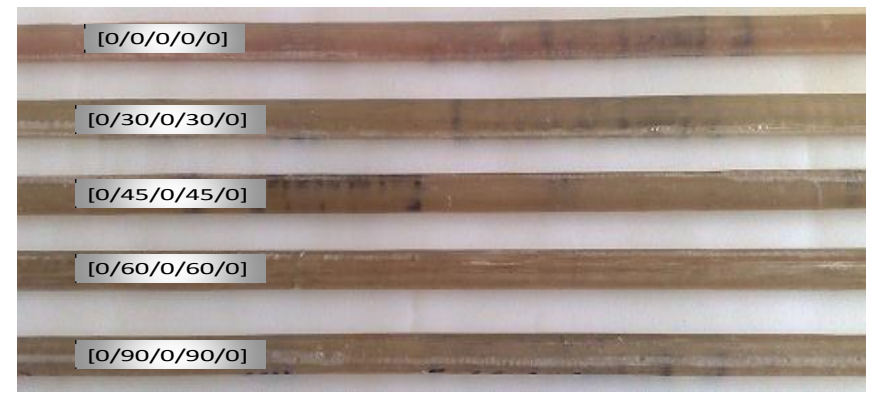

Fig. 4 Composite shafts manufacture.

\subsection{Critical Speed of Rotating Shaft}

This state occurs when the rotating speed of the shaft is equal to the natural frequency of lateral vibration of rotating shaft.

The rotor dynamic apparatus system used to measure and analyze the whirling phenomena is the TM1 whirling of shafts apparatus shown in Fig. 5 


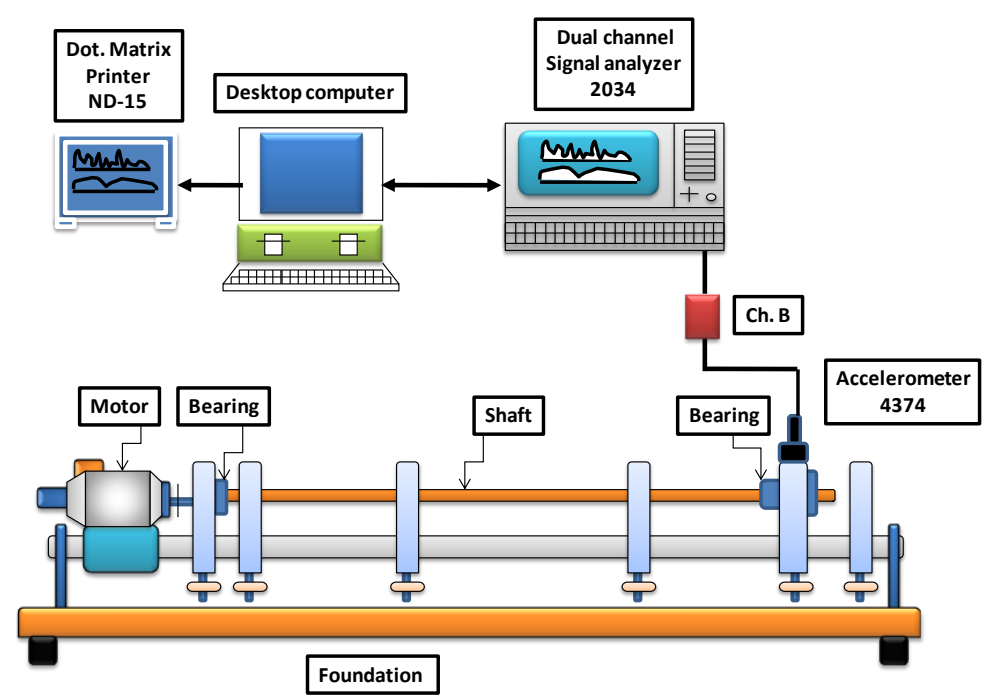

Fig. 5 TM1 MKII whirling of shafts machine.

The critical speed can be calculated related to the natural frequency of rotating shaft in this form

$$
n_{c r}=\frac{60}{2 \pi} \sqrt{\frac{g}{\delta}}
$$

The results from previous formula are calculated and presented in Table 3 at fiber volume fraction $\boldsymbol{V}_{\boldsymbol{f}}=\mathbf{6 5 \%}$. where: $\delta$ is the static deflection $=\left(\mathrm{W}_{\mathrm{s}} \mathrm{L}^{4} / \mathrm{E}_{\mathrm{c}} \mathrm{I}_{\mathrm{s}}\right)$ [19], $\boldsymbol{L}$ is the shaft length, $\boldsymbol{W}_{\boldsymbol{s}}$ is the shaft weight and $\boldsymbol{I}_{\boldsymbol{s}}$ is the moment of inertia of the shaft.

Table 3 Values of critical speed in [RPM] for various laminated orientations and different boundary fixation (theoretical result)

\begin{tabular}{l|c|c|c|c|c|c|c|c}
\hline \multirow{2}{*}{$\begin{array}{c}\text { Lamina } \\
\text { orientations }\end{array}$} & \multicolumn{2}{|c|}{ C-C } & \multicolumn{2}{c|}{ C-S } & \multicolumn{2}{c}{ S-S } & \multicolumn{2}{c}{ C-F } \\
\cline { 2 - 9 } & MI & MII & MI & MII & MI & MII & MI & MII \\
\hline$[0 / 0 / 0 / 0 / 0]$ & 15888 & 37374 & 10422 & 33732 & 6678 & 26698 & 2376 & - \\
\hline$[0 / 30 / 0 / 30 / 0]$ & 13290 & 31254 & 8712 & 28206 & 5574 & 22348 & 1986 & - \\
\hline$[0 / 45 / 0 / 45 / 0]$ & 10488 & 24672 & 6876 & 22266 & 4398 & 17622 & 1566 & - \\
\hline$[0 / 60 / 0 / 60 / 0]$ & 9066 & 21318 & 5946 & 19242 & 3798 & 15228 & 1356 & - \\
\hline$[0 / 90 / 0 / 90 / 0]$ & 7242 & 17028 & 4746 & 15372 & 3036 & 12163 & 1080 & - \\
\hline
\end{tabular}

\subsection{Experimental Modal of Vibration Damping of Composite Shaft FRP}

The frequency response tests were performed on composite shaft made from fiber reinforced plastic (FRP) by utilizing fast Fourier transform dual channel analyzer in conjunction with the computer as shown in Fig.5. The corresponding fundamental frequency and damping factor for various lamina orientation and different boundary conditions are measured and recorded using FFT analyzer in the range of $(800: 1600 \mathrm{~Hz})$. The comparison between theoretical analysis using FEM and Experimental measurements were performed and listed in Table 4. 
The peak response frequencies were identified from the peaks in the frequency spectra FRS. In addition, the system damping ratio $\xi$ was evaluated from the quality factor $\boldsymbol{Q}$ from $\boldsymbol{\omega}_{\boldsymbol{1}}$ and $\omega_{2}$ corresponding to half-power as:

$$
\mathrm{Q} \approx \frac{1}{2 \xi} \approx \frac{\omega_{\mathrm{n}}}{\omega_{2}-\omega_{1}}
$$

\subsection{Eigen Parameter Measurements}

The equation of motion of a damped multi degree of freedom system in matrix form:

$$
[M] \ddot{X}+[C] \dot{X}+[K] X=\{F\}
$$

By expressing the solution of $\mathrm{X}$ as a linear combination of the natural modes of the system as:

$$
X=x \cos (\omega t)
$$

\begin{tabular}{|c|c|c|c|c|c|c|c|c|c|c|c|c|c|}
\hline \multirow{3}{*}{\multicolumn{2}{|c|}{$\begin{array}{l}\text { Lamina } \\
\text { orientation and } \\
\text { boundary } \\
\text { fixations }\end{array}$}} & \multicolumn{3}{|c|}{$\mathrm{C}-\mathrm{C}$} & \multicolumn{3}{|c|}{ C-S } & \multicolumn{3}{|c|}{ S-S } & \multicolumn{3}{|c|}{ C-F } \\
\hline & & \multirow{2}{*}{$\xi$} & \multicolumn{2}{|c|}{$\mathrm{f},[\mathrm{Hz}]$} & \multirow{2}{*}{$\xi$} & \multicolumn{2}{|c|}{$\mathrm{f},[\mathrm{Hz}]$} & \multirow{2}{*}{$\xi$} & \multicolumn{2}{|c|}{$\mathrm{f},[\mathrm{Hz}]$} & \multirow{2}{*}{$\xi$} & \multicolumn{2}{|c|}{$\mathrm{f},[\mathrm{Hz}]$} \\
\hline & & & $\mathrm{Th}$ & Ex & & $\mathrm{Th}$ & Ex & & Th & Ex & & $\mathrm{Th}$ & Ex \\
\hline$[0 / 0 / 0 / 0 / 0]$ & \multirow{5}{*}{$\begin{array}{l}\partial^{0} \\
\stackrel{2}{1} \\
11 \\
>\end{array}$} & 0.112 & 264.8 & 260 & 0.136 & 173.7 & 167 & 0.146 & 111.3 & 109 & .176 & 39.6 & 37 \\
\hline$[0 / 30 / 0 / 30 / 0]$ & & 0.144 & 221.5 & 219 & 0.156 & 45.2 & 141 & 164 & & 87 & 196 & 33.1 & 29 \\
\hline$[0 / 45 / c$ & & 0.197 & 174.8 & 170 & 0.227 & 114.6 & 111 & 0.246 & & 70 & .347 & 26.1 & 21 \\
\hline$[0 / 60 / 0 / 60 / 0]$ & & 0.227 & 151.1 & 148 & 0.294 & 99.1 & 87 & 0.322 & 63. & 59 & 0.403 & 22.6 & 18 \\
\hline$[0 / 90$ & & 0.287 & 120.7 & 117 & 0.331 & 79.1 & 75 & 0.363 & 50. & 46 & 0.478 & 18.0 & 14 \\
\hline$[0 / 0 /$ & \multirow{5}{*}{ 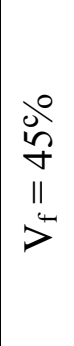 } & 0.095 & 320.4 & 318 & 0.114 & 210.1 & 208 & 0.140 & 131.3 & 129 & 0.170 & 47.1 & 44 \\
\hline$[0 / 30 /$ & & 0.127 & 268.1 & 263 & 0.143 & 173.6 & 169 & 0.159 & 114.4 & 113 & 0.192 & 40.1 & 38 \\
\hline$[0 / 45 / 0 / 45 / 0]$ & & 0.156 & 211.5 & 207 & 0.183 & 136.4 & 134 & 0.219 & 87.3 & 85 & 0.296 & 31.5 & 29 \\
\hline$[0 / 60 / 0 / 60 / 0]$ & & 0.199 & 182.3 & 177 & 0.235 & 116.2 & 115 & 0.273 & 76.3 & 74 & 0.365 & 27.3 & 26 \\
\hline$[0 / 90 / 0 / 90 / 0$ & & 0.243 & 145.4 & 140 & 0.292 & 95.1 & 90 & 0.314 & 62.2 & 00 & 0.425 & 21.3 & 20 \\
\hline$[0 / 0 / 0 / 0 / 0]$ & \multirow{5}{*}{$\begin{array}{l}0^{0} \\
i b \\
11 \\
>\end{array}$} & 0.061 & 396.2 & 392 & 0.091 & 258.4 & 255 & 0.135 & 164.3 & 161 & 0.165 & 58.4 & 56 \\
\hline$[0 / 30 / 0 / 30 / 0]$ & & 0.105 & 328.1 & 326 & 0.121 & 216.3 & 214 & 0.155 & 137.1 & 135 & 0.186 & 48.2 & 43 \\
\hline$[0 / 45 /$ & & 0.134 & 257.3 & 253 & 0.164 & 167.1 & 163 & 0.188 & 108.2 & 105 & 0.232 & 38.1 & 35 \\
\hline$[0 / 60 / 0 / 60 / 0]$ & & 0.169 & 226.2 & 224 & 0.197 & 144.2 & 141 & 0.237 & 93.4 & 89 & 0.291 & 33.3 & 30 \\
\hline [0/90/0/90/0] & & 0.196 & 175.4 & 172 & 0.231 & 113.7 & 109 & 0.291 & 74.2 & 71 & 0.348 & 26.5 & 24 \\
\hline
\end{tabular}

Table 4 Values of fundamental frequency in $\mathrm{Hz}$ and damping factor “ $\xi$ ” for various laminated orientations and different boundary fixation 
Table 5 The damping factors, natural frequency and coefficients $\alpha$ and $\beta$.

\begin{tabular}{|c|c|c|c|c|c|c|c|}
\hline \multicolumn{2}{|c|}{ Lamina orientation } & ${ }_{1} \xi$ & ${ }_{2} \xi$ & ${ }_{1} \omega$ & ${ }_{2} \omega$ & $\alpha$ & $\beta$ \\
\hline$[0 / 0 / 0 / 0 / 0]$ & \multirow{5}{*}{$\begin{array}{l}00 \\
\stackrel{2}{2} \\
\text { II } \\
>\end{array}$} & 0.112 & 0.107 & 264.8 & 432.2 & 39.38 & $2.84 * 10^{-4}$ \\
\hline$[0 / 30 / 0 / 30 / 0]$ & & 0.144 & 0.136 & 221.5 & 361.5 & 43.03 & $4.23 * 10^{-4}$ \\
\hline$[0 / 45 / 0 / 45 / 0]$ & & 0.197 & 0.191 & 174.8 & 285.3 & 44.76 & $7.89 * 10^{-4}$ \\
\hline$[0 / 60 / 0 / 60 / 0]$ & & 0.227 & 0.220 & 151.1 & 246.6 & 44.61 & $1.1 * 10^{-3}$ \\
\hline [0/90/0/90/0] & & 0.287 & 0.281 & 120.7 & 196.7 & 44.36 & $1.7 * 10^{-3}$ \\
\hline$[0 / 0 / 0 / 0 / 0]$ & \multirow{5}{*}{$\begin{array}{l}\stackrel{0}{2} \\
\stackrel{n}{7} \\
\|^{4} \\
p^{4}\end{array}$} & 0.095 & 0.087 & 320.4 & 522.8 & 42.8 & $1.76^{*} 10^{-4}$ \\
\hline$[0 / 30 / 0 / 30 / 0]$ & & 0.127 & 0.122 & 268.1 & 437.5 & 44.85 & $3.23 * 10^{-4}$ \\
\hline$[0 / 45 / 0 / 45 / 0]$ & & 0.156 & 0.150 & 211.5 & 345.2 & 43.41 & $5.05 * 10^{-4}$ \\
\hline$[0 / 60 / 0 / 60 / 0]$ & & 0.182 & 0.177 & 182.3 & 297.5 & 42.93 & $7.04 * 10^{-4}$ \\
\hline$[0 / 90 / 0 / 90 / 0]$ & & 0.243 & 0.236 & 145.4 & 237.3 & 85.81 & $1.2 * 10^{-3}$ \\
\hline$[0 / 0 / 0 / 0 / 0]$ & \multirow{5}{*}{$\begin{array}{l}00 \\
\tilde{0} \\
\|^{2} \\
>^{4}\end{array}$} & 0.061 & 0.053 & 396.2 & 672.9 & 5.59 & $2.72 * 10^{-4}$ \\
\hline$[0 / 30 / 0 / 30 / 0]$ & & 0.105 & 0.101 & 328.1 & 540.9 & 45.41 & $2.18 * 10^{-4}$ \\
\hline$[0 / 45 / 0 / 45 / 0]$ & & 0.134 & 0.128 & 257.3 & 431.2 & 46.04 & $3.46 * 10^{-4}$ \\
\hline$[0 / 60 / 0 / 60 / 0]$ & & 0.169 & 0.162 & 226.2 & 385.3 & 51.01 & $4.97 * 10^{-4}$ \\
\hline$[0 / 90 / 0 / 90 / 0]$ & & 0.196 & 0.190 & 175.4 & 323.8 & 46.21 & $7.33 * 10^{-4}$ \\
\hline
\end{tabular}

For the applied harmonic load of $F=f \cos (\omega t)$ at the rotating composite shaft

By substituting Eqn. 10 into Eqn. 9, one obtains

$$
\begin{gathered}
\{x\}=\left[-\omega^{2}[M]+j \omega[C]+[K]\right]^{-1}\{f\} \\
{[C]=\alpha[M]+\beta[K]} \\
{[C][K]^{-1}[M]=[M][K]^{-1}[C]} \\
\xi_{i}=\frac{\alpha}{2 \omega_{i}}+\frac{\beta \omega_{i}}{2}
\end{gathered}
$$

The eigen value problem of proportional damped system can be resolved to two standard eigen value problem [20] and the form.

$$
\begin{gathered}
{\left[[M]^{-1}[K]-\omega^{2}[I]\right]=0} \\
{\left[[M]^{-1}[C]-u[I]\right]=0}
\end{gathered}
$$

The damping matrix [C] can be calculated as a proportional damping (Rayleigh damping) as shown in Eqn. 12, where $\boldsymbol{\alpha}$ and $\boldsymbol{\beta}$ are coefficients determined by experimental investigation. The necessary and sufficient conditions of proportional damping system are given by Eqn. 13 . In this case, the response of the rotating composite shaft was separated into the responses at each mode by spectral analysis and the damping ratio $\xi_{i}$ and coefficients $\boldsymbol{\alpha}$ and $\boldsymbol{\beta}$ are identified by Eqn. 14 .

The results of the coefficients $\alpha$ and $\beta$ are listed in Table 5 where: $\xi_{i}$ and $\omega_{i}$ are the damping ratio and natural frequency of $\boldsymbol{i}^{\text {th }}$ mode respectively and $\boldsymbol{u}$ is the eigen values of inertia damping matrix, $\boldsymbol{u}=\mathbf{2} \boldsymbol{\xi} \boldsymbol{\omega}$. 
The specimen location in the $\boldsymbol{T M 1}$ whirling of shafts apparatus and the boundary conditions can be achieved using suitable bearing then the ratio of clearance and bush bearing width adjustable.

\section{Results and Discussion}

The dynamic analysis of laminated composite rotating shaft with various fiber orientations and different boundary fixations, are investigated analytically and experimentally. The fiber orientation, critical whirling speed and boundary fixation of the rotating composite shaft have significant influences on the dynamic properties taking into account the types of fiber, and matrix materials. The equivalent stiffness and mass of laminated composite shaft have been derived by using the lamination theory. The eigen parameters can be computed using Dunkerley approach for dynamic analysis of rotating composite shaft have been proposed. The specimens of orientation sequences [0]5 and [0/90/0/90/0] have highest and lowest frequencies respectively compared with the specimen of the other orientation sequences for the same boundary fixation. This was expected since its orientations sequences make the rotating composite shaft more stiff in the respective direction.

A possible increase of both the flexural frequency and damping ratio can be achieved by applying a very stiff and light material for the constraining shaft, such as high modulus is achieved using specimen of fiber orientation [0\0\0\0\0] and high damping factors in the specimen of [01901019010] fiber orientation. However, the added cost of this special material application, does not justify the slight increase in both frequency and damping. When the spinning speed is considered, the branching effect of both the fundamental frequency and damping ratio is observed. That is, as the shaft spins, the natural frequency as well as the damping ratio splits into a lower and a higher value. As the spinning speed increases, the two split values branch off farther apart.

The mechanical properties, eigen parameters and critical speed of rotating composite shafts are presented and discussed from experimental and analytical work. Various specimens of different orientations are fabricated utilizing winding layup method.

The developed discrete equation (6) is solved for the natural frequencies and damping ratios using MATLAB. The current analysis is mainly for non-spinning shafts $(\Omega=0)$. However, the effect of the spinning speed is covered at the end of the present work in order to demonstrate the branching phenomenon observed in the case of the vibration of rotating shafts. Since the analysis is concerned primarily with finding the fundamental flexural natural frequency of the shaft, which limits the frequency range studied.

Three sets of results are presented. The first set is aimed at checking the validity of the mathematical model and techniques of solution (EXM and FEM). In the second set, a parametric study is conducted to investigate the effect of geometric and material parameters on the fundamental flexural frequency and damping ratio of the constrained layer treated shaft. The third set presents the effect of the spinning speed on the fundamental flexural natural frequency and damping ratio.

\subsection{Effect of Stacking Sequences and Fiber Volume Fraction on Eigen Parameters and Critical Speed}

Figure 6-(a) shows the effect of stacking sequences and fiber volume fraction on frequency value based on mathematical modeling under clamped-clamped boundary fixation. From 
Fig. 6-(a) it can be noted that the frequency values significantly varied with the state of stacking sequences. This is due to the fact that outer staking layer has more effect on the stiffness compared with the inner layer. The fiber volume fraction has slightl effect on the eigen parameters. For the specimen $[0 / 0 / 0 / 0 / 0]$ and volume fraction $65 \%$, frequency values slightly increase. The low value of frequency at [0/90/0/90/0] and volume fraction $25 \%$ may be attributed to the low level of potential energy at this condition.

In view of lamina orientations, the rate of change of the critical speed via fiber volume fraction is relatively high compared with the rate of change due lamina orientations as shown in Fig. 6-(b). From Fig. 6-(b), it can be observed that specimen [0/90/0/90/0] has the lowest critical speed compared with the other specimen while the specimen [0]5 has the highest values this is due to the minimum and maximum values of flexural elastic modules and stiffness at this orientation respectively. The change of lamina orientations from $[0 / 0 / 0 / 0 / 0]$ to $[0 / 90 / 0 / 90 / 0]$ decreases by $54.4 \%$.

From Figs. 6 (a) and (b) it can be noted that, the fiber volume fraction has a limited effect on frequency and critical speed value because the effect of lamina orientations has a dominant influence.

From Fig. 6 (c), it can be observed that specimen [0/90/0/90/0] has the lowest critical speed compared with the other specimen while the specimen $[0 / 0 / 0 / 0 / 0]$ has the highest values this is due to the minimum and maximum values of flexural elastic modules and stiffness at this orientation respectively. In view of different fixation, the rate of change of the critical speed via different fixations are relatively high compared with the rate of change due to the use of the various code numbers of fiber orientations as shown in Fig. 6 (c) and Table 2.

Figure 6 (d) declares the effect of stacking sequences and fiber volume fraction on damping factor under one case of clamped-clamped boundary fixation. It is clear that the damping factor values significantly varied with the state of lamina orientations and fiber volume fraction in a reverse trend as compared with frequency Fig. 6. (a) The high value of damping factor occurs under [0/90/0/90/0] and $25 \%$ volume fraction.

\subsection{Campbell Diagram}

The Campbell diagrams shown in Fig. 7, representing the evolution of natural frequency with respect to the speed of rotation, illustrate the significant influence of stacking sequences on frequencies and instability thresholds.

In Fig. 7 the composite rotor is in a balanced and symmetrical configuration: [0/0/0/0/0]. In this case, instabilities (symbolized in the figure) occur just after the second critical speed.

The Campbell diagrams associated with the fifth sequences Table 4 are presented, respectively in Fig. 7 and illustrate the advantage of using stacking sequences as an optimization parameter for both frequencies and instability thresholds. The differences between the two configurations is up to $51 \%$ for frequencies at rest for the first forward whirl $(\boldsymbol{F W})$ and about $31.25 \%$ for instability thresholds $(2750$ and $\mathbf{4 0 0 0} \mathbf{~ r p m})$. For the fifth sequence, rotor speed can exceed the third critical speed without generating instability, whereas, instability occurs at speeds higher than the second critical speed for the second sequence. Such behavior is explained by the fact that the greater the number of fibers oriented close to the longitudinal direction of the rotating composite shaft, the more they contribute to shaft rigidity and, consequently, the higher frequencies are. In parallel, the lower the 
orientation angle, the lower the internal damping due to the composite materials is and, consequently, the later instability occurs.

\subsection{Dynamic Response of Rotating Composite Shaft}

Programming codes based Matlab program, version (7.1) are implemented to analyze the dynamic response of the rotating composite shaft under autogenously excitation on the bases from the experimental test. The analysis are performed for composite shaft of three types of fiber volume fraction $(\mathbf{2 5 \%}, \mathbf{4 5 \%}$, and $\mathbf{6 5 \%})$ and various types of lamina fiber orientations.

Figures 8 represent the frequency response of the composite shaft at the clamped-clamped boundary fixation of the specimen with three types of fiber volume fraction and different types of fiber lamina orientations. The results indicate that there is apparently a correlation between the theoretical and experimental results, Table 4, shows the damping factors, natural frequency for three types of fiber volume fraction and various lamina orientations and the coefficients $\boldsymbol{\alpha}$ and $\boldsymbol{\beta}$.

From Fig. 8 it can be noticed that the amplitude of specimens [0/90/0/90/0] are higher than those of the other specimen and $[\mathbf{0 / 0 / 0 / 0 / 0}]$ has lower ones. And the maximum amplitude at $25 \%$ fiber volume fraction compared with the $\mathbf{6 5 \%}$ fiber volume fraction by almost $0.9 \%$.

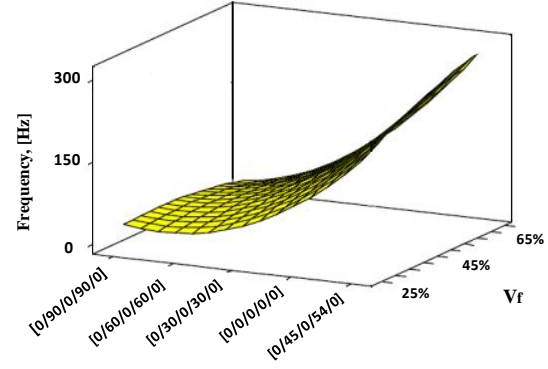

Lamina Orientations

(a)

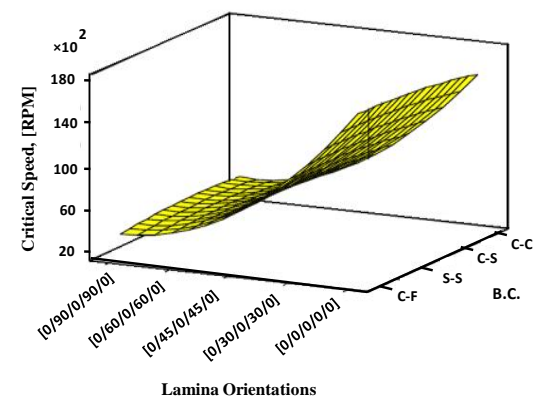

(c)

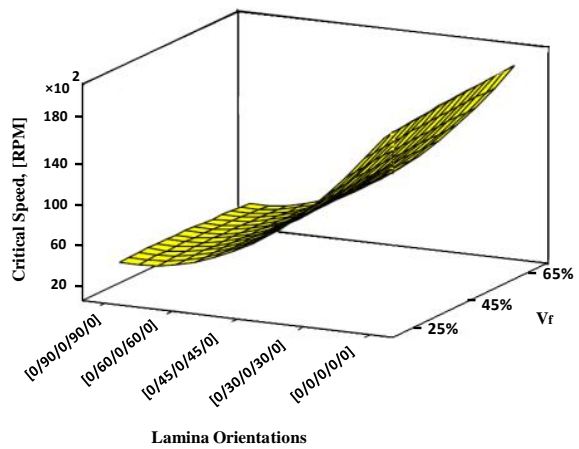

(b)

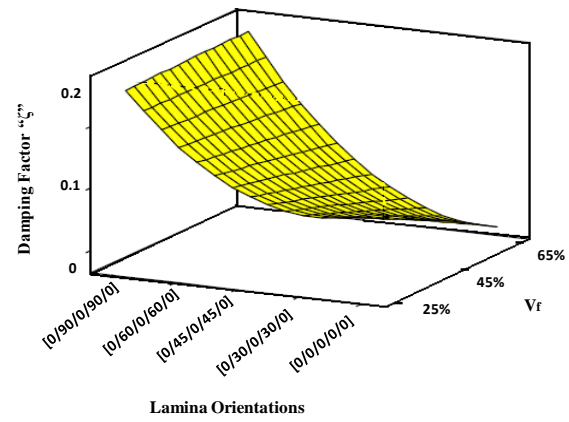

(d)

Fig. 6 Effect of lamina orientations on frequency, critical speed and damping factor at different fiber volume fractions. 

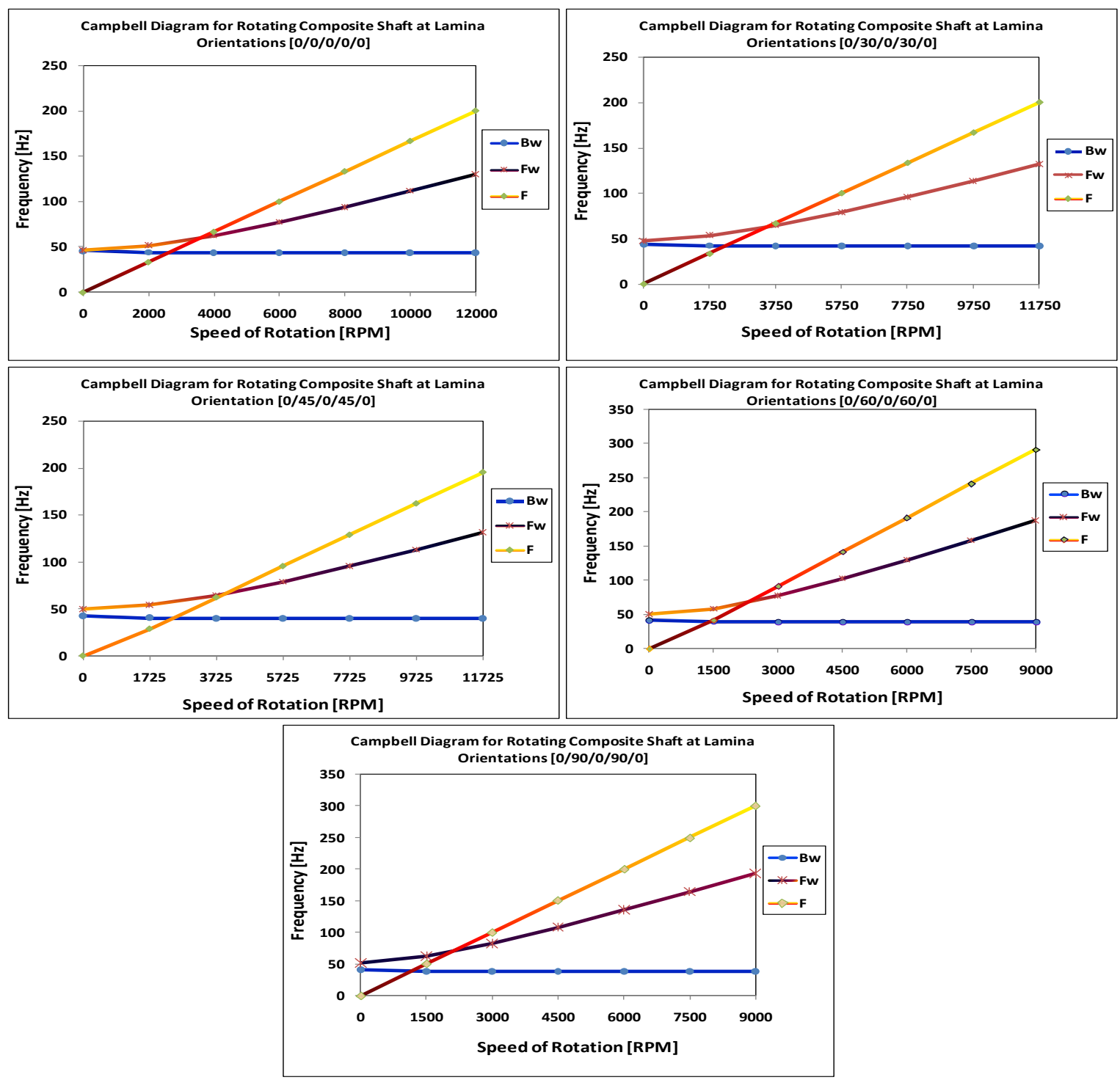

Fig. 7 Campbell diagram and instability regions with various types of lamina orientations.

\section{Conclusions}

The dynamic analysis of laminated composite shaft with different fiber orientations, three level of fiber volume fraction and four boundary fixations are investigated analytically and experimentally. From the numerical and experimental results one can conclude:

- For prediction of the dynamic analysis of composite shaft Campbell diagram present a suitable tool for controlling the rotating to achieve accuracy and overcome critical speed in resonance state.

- The present comparison between the numerical and experimental results proves that the suggested finite element models of the composite structural shaft with boundary fixations provide an efficient tool for the dynamic analysis with proper accuracy. 
- The avoidance of rapid failure of the composite shaft due to the shear effect (particularly at the resonant modes) can be attained by selecting the proper fixation type for example the composite shaft with clamped-clamped fixation and lamina orientation [0/45/0/45/0] is more convenient.

- It can be control of the dynamic behavior of composite shaft for the operation state through stiffness, high damping capacity and low inertia.

- The developed proportional damping by utilizing the proper weight factors permits the utilization of normal coordinate systems for uncoupling equations of motion of composite structure with the high confidence level at $99.5 \%$.

- Dynamic response gives proper information about resonance avoidance for certain operation conditions particularly composite shaft. In the other hand mode shape provides information about vibration level and the location of nodes and modes at each position. These important parameters from designers point of view.
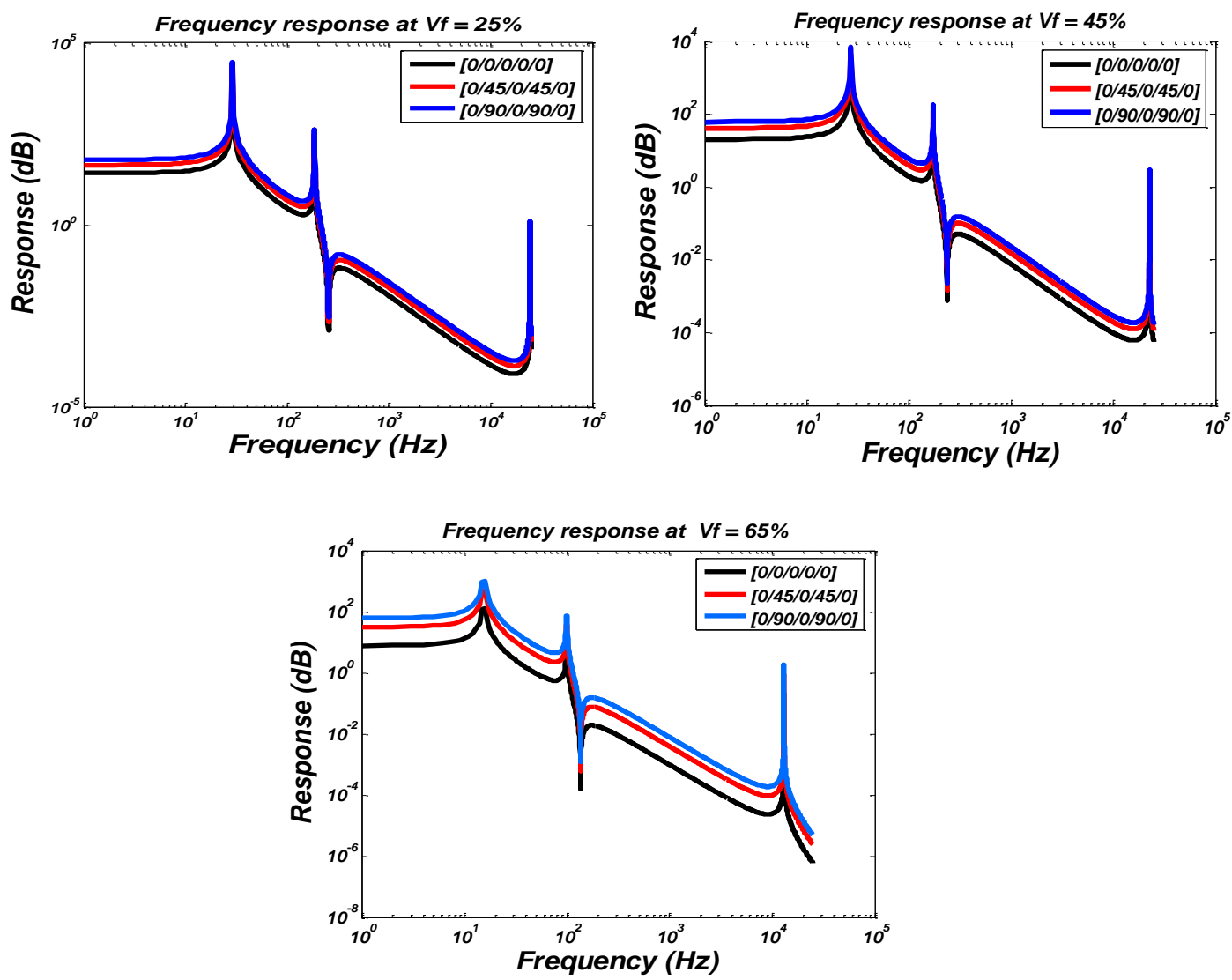

Fig. 8 Results of the theoretical model for the frequency response of the rotating composite shaft at three types of fiber volume fraction and various types of fiber lamina orientations. 


\section{References}

[1] O. Bauchau, Optimal design of high speed rotating graphite/epoxy shafts, J Compos Mater, Vol. 17 (3),170-81, (1983).

[2] E. Chatelet, D. Lornage, and G. Jacquet-Richardet, Dynamic behavior of thin-walled composite shafts: a three dimensional approach, In: Fifth annual engineering system design and analysis conference, ASME, Montreux Switzerland, 1-5, (2000).

[3] LW. Chen, and WK. Peng, Dynamic stability of rotating composite shafts under periodic axial compressive loads, J Sound Vib. Vol. 212 (2), 215-30, (1998).

[4] MS. Darlow and J. Creonte, Optimal design of composite helicopter power transmission shafts with axially varying fiber lay-up, J Am Helicopter Soc, Vol. 40 (2), 50-60, (1995).

[5] Y.S. Lee and Y.W. Kim, Nonlinear free vibration analysis of rotating hybrid cylindrical shells, Computers and Structures, Vol. 70, 161-168, (1999).

[6] JC. Pereira and ME. Silveira, Evaluation and optimization of the instability regions on rotors in wounding shaft, In: II congress nacional de engenharia mechanic, Joaho Pessoa, (2002).

[7] AL. Kimball, Internal friction as a cause of shaft whirling, Philos Mag., Vol. 49(1):724, (1925).

[8] M. Lalanne and G. Ferraris, Rotordynamics prediction in engineering, 2nd ed. John Wiley and Sons, (1998).

[9] H. Ghoneim and D. J. Lawrie, Analysis of the Flexural Vibration of a Composite Drive Shaft with Partial Cylindrical Constrained Layer Damping Treatment, Journal of Vibration and Control, Vol. 12(1), 25-55, (2006).

[10] V. Tita, J .de Carvalho and J. Lirani, Theoretical and experimental dynamic analysis of fiber reinforced composite beams, J. of the Braz. Soc. Mech. Sci. 7 Eng. XXV, Vol. 3 p. 306, (2003).

[11] S. M. Ghoneam, A. A. Hamada and M. I. EL-Elamy, Experimental and Analytical Investigations of the Dynamic Analysis of Adhesively Bonded Joints for Composite Structures, Solid State Phenomena Vols. 147-149 p. 663-675, (2009).

[12] J. Richardet, E. Chatelet and D. Lornage, A three dimensional modeling of the dynamic behavior of composite rotors, Proceedings of ISROMAC-8 (The 8th International Symposium on Transport Phenomena and Dynamics of Rotating Machinery), March 2000, Honolulu, Hawaii, USA, p. 988-994, (2000).

[13] H.B.H. Gubran, Dynamics of hybrid shafts, Mechanics Research Communications, Vol. 32 368-374, (2005).

[14] M. Guo, I.E. Harik and W.X. Ren, Free vibration analysis of stiffened laminated plates using layered finite element method, Structural Engineering and Mechanics, Vol. 14 (3), 245-262, (2002).

[15] M. R. Hatch, Vibration simulation using Matlab and Ansys, Chapman and Hall/CRC, (2001).

[16] R.M. Jones, Mechanics of Composite Materials, Scripta Book Co., Washingtion, D.C. 1975.

[17] F.M. Dimentberg, Flexural Vibrations of Rotating Shafts, Butterworths, (1961).

[18] Z. Kristin and L. Dahsin, Geometrical parameters in composite repair, Journal of Composite Materials, Vol. 29, (11), p. 1473, (1995).

[19] S. Rao, Mechanical Vibrations, SI Edition, Prentice Hall, New York, (2004).

[20] A. Maher, Notes on Dynamic of machine, Printed Lecture p. 3-3 - 3-4, (2000). 